\title{
Prevalence of Curable Sexually Transmitted Infections in Pregnant Women in Low- and Middle-Income Countries From 2010 to 2015:
}

\section{A Systematic Review}

DL Joseph Davey, MPH, PhD ${ }^{*} \dagger$, HI Shull, MD, JD Billings ${ }^{\star}, D^{*}$ Wang ${ }^{\ddagger}$, K Adachi, MD ${ }^{\star}$, and JD Klausner, MD, MPH ${ }^{\star}, \dagger$

*David Geffen School of Medicine at UCLA, UCLA, Los Angeles, CA

†Fielding School of Public Health, Department of Epidemiology, UCLA, Los Angeles, CA

‡Fielding School of Public Health, Department of Biostatistics, UCLA, Los Angeles, CA

\section{Abstract}

Background-Current literature comparing the prevalence rates of curable sexually transmitted infections (STIs) in pregnant women in various global regions is limited. As a result, antenatal screening practices for curable STIs in pregnant women, specifically Treponema pallidum (syphilis), Neisseria gonorrhoeae (NG), Chlamydia trachomatis (CT), and Trichomonas vaginalis (TV) vary around the world, differing by country and particular STI.

\begin{abstract}
Methods-We conducted a systematic review of publications on STI prevalence among pregnant women in 30 different low- and middle-income countries. We searched PubMed for studies reporting prevalence of syphilis, CT, NG, and TV in pregnant women. English language studies published between January 1, 2010, and March 1, 2015, were included. The adjusted mean STI prevalence by region was calculated via multivariable linear regression adjusting for health care setting, women's mean age, study sample size, and sensitivity of diagnostic test.
\end{abstract}

Results-We identified 75 studies that met inclusion criteria, providing 116 point prevalence estimates for curable STIs among 3,489,621 pregnant women. Adjusted mean prevalence for NG ranged from $1.2 \%$ (95\% confidence interval [CI], 1.0-1.3) in Latin America to 4.6\% (95\% CI, 4.0-5.2) in Southern Africa; syphilis prevalence ranged from 1.1\% (95\% CI, 0.5-1.6) in Asia to 6.5\% (95\% CI, 4.7-6.3) in Southern Africa; CT ranged from 0.8\% (95\% CI, 0.4-1.1) in Asia to $11.2 \%$ (95\% CI, 6.0-16.4) in Latin America; and TV ranged from 3.9\% (95\% CI, 2.2-5.6) in Latin America to $24.6 \%$ (95\% CI, 17.9-31.4) in Southern Africa.

Conclusions-Although we observed a wide variation in STI burden in pregnancy after adjusting for age, test, and health care setting, further valid comparison may depend on adjustment for access to care and screening practices.

Correspondence: Dvora Joseph Davey, MPH, PhD, University of California, Los Angeles Los Angeles, CA. dvoradavey@ucla.edu. Conflict of interest: None declared. 
Curable sexually transmitted infections (STIs) in pregnant women, specifically Treponema pallidum (syphilis), Neisseria gonorrhoeae (NG), Chlamydia trachomatis (CT), and Trichomonas vaginalis (TV), may lead to various adverse outcomes including premature rupture of membranes, preterm labor, preterm delivery, chorioamnionitis, low birth weight, congenital infection, and even stillbirth or neonatal mortality. ${ }^{1-9}$ Furthermore, recent studies have suggested the possibility of increased mother-to-child transmission of human immunodeficiency virus (HIV) among mothers with bacterial STIs. ${ }^{3,10,11}$

Antenatal screening practices for curable STIs vary around the world, differing by country and particular STI. The World Health Organization (WHO) has implemented guidelines for testing and treatment of syphilis in pregnancy. Early successes of the congenital syphilis elimination program have been demonstrated by the elimination of mother-to-child transmission of syphilis in Cuba. ${ }^{12-14}$ However, no WHO recommendations exist for the screening of $\mathrm{CT}$ and NG in pregnancy. Although the screening of asymptomatic pregnant women at increased risk for CT and NG is currently standard of care in the United States, ${ }^{15}$ WHO recommends a syndromic approach with presumptive treatment for symptomatic women. ${ }^{10}$ Because most CT and NG infections are asymptomatic, syndromic management misses the majority of the $\mathrm{CT}$ and NG infections in pregnancy.

Current literature comparing the prevalence rates of curable STIs in various global regions is limited. A recent review article by Chico et al. ${ }^{16}$ focused on sub-Saharan Africa, but an update of this region and other global regions has not been performed. Our systematic review summarizes the adjusted mean prevalence of curable STIs among pregnant women in low- and middle-income countries, stratified by geographic region, and adjusting for potential confounders. The Chico review covered sub-Saharan Africa, which is predominately low income.

\section{METHODS}

We used the PRISMA guidelines to conduct a systematic review to assess the prevalence of CT, NG, TV and syphilis in pregnancy from studies published between January 1, 2010, and March 1, 2015. The cited data were collected earlier in many studies, ranging from 1999 to 2014. ${ }^{17}$ PubMed was searched to identify studies based on the following inclusion criteria: (1) English language; (2) cross-sectional/prevalence, cohort, or case-control study design; (3) conducted in a low- or middle-income country; and (4) reported on prevalence statistics for pregnant women. Exclusion criteria included (1) non-English language, (2) review article, (3) study conducted outside of a low- or middle-income country, (4) sample from women previously tested for STIs during current pregnancy, (5) data collected after postpartum women were discharged from the hospital, (6) data obtained via surveys or selfreport, and (7) data obtained from high-risk pregnant women (eg, pregnant sex workers), and/or cohort of women presenting with a chief complaint of vaginal discharge (Fig. 1). H.S. reviewed the PubMed search results, and D.J.D. cross-checked results, validated the data, and resolved discrepancies. We excluded studies on sex workers, women with ectopic pregnancy and symptomatic women; however, we did include HIV-infected pregnant women in the analysis. We did not have exclusion criteria based on testing or screening protocols, other than excluding studies if the testing was syndromic or if the results were self-reported. 
There were no requirements for sample size for the selected articles, though the sample size was adjusted for in the analysis.

Definitions of low- and middle-income countries were obtained from the World Bank (http:// data.worldbank.org/incomelevel/LMY). When a study reported more than 1 STI prevalence, we recorded each infection and each sample size separately. Data abstraction was not blinded to authors or publication, but was performed independently. See Supplemental file for a complete list of publications included in the analysis.

We stratified our prevalence estimates by region and adjusted for health care setting (eg, hospital-, clinic-, or community-based study), age of pregnant women in the study, and diagnostic tests used. Prevalence values in the included articles were calculated as the number of pregnant women who were diagnosed with an STI over the total number of pregnant women tested.

For syphilis, tests included venereal disease research laboratory, rapid plasma reagin, Treponema pallidum hemagglutination, Toluidine Red Unheated Serum Test, Treponema pallidum particle agglutination assay, enzyme immunoassay, fluorescent treponemal antibody absorption, and rapid diagnostic test. However, 23 of 54 (43\%) studies on syphilis only reported venereal disease research laboratory, rapid plasma reagin, or Treponema pallidum hemagglutination but no second test. For CT and NG, tests included nucleic acid amplification testing (NAAT), enzyme immunoassay, IgG antibody screen, culture, Aptima combo 2 and microscopy. For TV, tests included polymerase chain reaction, culture, and microscopy. Data for diagnostic test used was extracted from the studied articles. Due to the variance in performance of different diagnostic tests, estimated sensitivities and specificities were collected from the current literature for each reported diagnostic test used. ${ }^{18-22}$

All studies that satisfied the previously mentioned inclusion criteria were analyzed and those with missing data points for any factors are denoted in the final analysis. Site of data collection was stratified in a stepdown method to 3 subgroups: at a hospital, at an antenatal or community clinic, or as part of a study or community screening program. Studies reporting more than 1 type of location for data collection or crossover within a location, that is, an antenatal clinic within a hospital, were considered to have occurred at the higher-level care center. Studies directly reporting mean or median ages for the women were used for portion of the analysis whereas studies that either stratified age as a categorical variable without reporting mean age or did not report age as a factor were noted as missing in the final analysis.

\section{Statistical Analyses}

We stratified results by subregion (East Africa, West Africa, Southern Africa, Latin America, and Asia). Asia included South Asia, and the Middle East and Pacific Regions, and Latin American included both Central and South America, due to the small number of studies from these regions. We calculated the total number of positive pregnant women per STI per region, the median number with positive diagnoses, the study sample size, the mean age, and the mean sensitivity and specificity for each diagnostic test used (if not counted, then was reported as missing). We developed multivariable linear regression models to 
estimate adjusted mean prevalence by STI and region, and 95\% confidence intervals (CI) for all strata. We adjusted for health care setting (eg, hospital-, clinic-, or community-based study), women's mean age, study sample size, and STI test sensitivity. The specificity was not included in the final model due to collinearity with sensitivity. We used STATA 13.1 (College Station, TX) for all analyses. ${ }^{23}$

\section{RESULTS}

We identified a total of 376 potentially relevant reports from January 2010 to March 2015. Only 75 studies from 30 low- and middle-income countries met inclusion criteria, providing 116 point prevalence estimates for curable STIs in pregnant women, including a total of $3,489,621$ women (Fig. 1). The diagnostic test used was reported in $94.7 \%$ of included articles. The greatest number of published studies were from Latin America ( $\mathrm{n}=23$ studies, $\mathrm{n}=206,848$ pregnant women), followed by East Africa ( $\mathrm{n}=20$ studies, $\mathrm{n}=23,413$ pregnant women), Asia ( $\mathrm{n}=18$ studies, $\mathrm{n}=3,109,314$ pregnant women), Southern Africa ( $\mathrm{n}=15$ studies, $\mathrm{n}=128,467$ pregnant women), and West Africa ( $\mathrm{n}=6$ studies, $\mathrm{n}=10,790$ pregnant women). The total number of studies is greater than the 75 studies included because some studies had more than 1 country in the analysis. The number of women and numbers of tests per woman varied considerably from a sample size of 12 (in Brazil) to a sample size of over 2 million (in China).

Overall, the region with the highest adjusted mean prevalence of curable STIs among pregnant women was Southern Africa. Our analyses included studies in the following countries: South Africa, Malawi, Madagascar, Zambia, Mozambique, and Zimbabwe. In Southern Africa, TV was the most prevalent STI overall, with a adjusted mean prevalence of $24.6 \%$ (95\% CI, 17.9-31.4) in 3 studies. Next was syphilis with a prevalence of 6.5\% (95\% CI, 4.70-8.3) in 8 studies. Neisseria gonorrhoeae and CT were similarly high at $4.6 \%$ (95\% CI, 4.0-5.2) in 3 studies, and 4.4\% (95\% CI, 2.3-6.6) in 3 studies, respectively (Fig. 2).

In East Africa, we included studies from the following countries: Kenya, Tanzania, Somalia, Ethiopia, Uganda, and Sudan. Eight studies demonstrated a adjusted mean prevalence of syphilis of 4.6\% (95\% CI, 3.7-5.4), the second highest prevalence after Southern Africa. The adjusted mean prevalence was similarly high for TV in 3 studies at $6.8 \%$ (95\% CI, 4.69.0). The adjusted mean prevalence of $\mathrm{CT}$ in 3 studies was $4.2 \%$ (95\% CI, 2.8-5.6), followed by NG with a prevalence of $2.3 \%$ (95\% CI, 2.0-2.5) in 3 studies (Fig. 2).

In West Africa, we included studies from Benin, Democratic Republic of Congo, Nigeria, and Burkina Faso. In these countries, the adjusted mean prevalence of CT was 7.2\% (95\% CI, 0.0-14.6) in 1 study. The adjusted mean prevalence of syphilis was $4.0 \%$ (95\% CI, $1.7-$ 6.3 ) in 4 studies (Fig. 2).

For Latin America, we included studies from Peru, Brazil, Ecuador, Argentina, and Guatemala. The adjusted mean prevalence of TV among pregnant women was 3.9\% (95\% CI, 1.1-5.6) in the 3 studies included. The adjusted mean prevalence of CT in Latin America was $11.2 \%$ (95\% CI, 7.3-17.1) in 7 studies, which is higher than the mean prevalence in Southern and East Africa. Syphilis had a mean prevalence of 2.6\% (95\% CI, 1.2-3.9) in 15 
studies. The mean prevalence of NG was very low at $0.3 \%$ (95\% CI, 0.1-2.1) in 3 studies (Fig. 2).

In Asia, we included studies from China, India, Bangladesh, Papua New Guinea, Turkey, Pakistan, Iran, Myanmar, and Cambodia. The mean prevalence of STIs among pregnant women was lower here than the other regions. Trichomonas vaginalis was most prevalent with a mean prevalence of $13.6 \%(95 \% \mathrm{CI}, 6.8-20.4)$ in 1 study, followed by NG at $2.8 \%$ (95\% CI, 2.4-3.3) in 1 study, and CT at $0.8 \%$ (95\% CI, 0.4-1.1) in 6 studies. The mean prevalence of syphilis was also lowest in Asia at 1.1\% (95\% CI, 0.5-1.6) in 13 studies controlling for potential confounders (see Table 1).

\section{DISCUSSION}

Our study found that the prevalence of curable STIs among pregnant women was substantial throughout low- and middle-income countries. Importantly, our review found a lack of recent data on STI prevalence among pregnant women in many parts of the world. We also note that the variation in diagnostic tests used and populations tested makes it difficult to compare the prevalence between the different regions. Inconsistencies between research and practice may play a role in why the WHO has not implemented clear screening guidelines and policies for STI screening, other than for syphilis and HIV, in pregnancy. ${ }^{13,14}$ In most high-income countries, NAATs are the diagnostic standard of care for NG and CT due to their wide availability and high sensitivity and specificity. ${ }^{15,16,18-23}$ Yet, many other nations have no tests available or rely on tests with lower sensitivities and specificities. Cultures for NG and CT have estimated sensitivities of $41 \%$ and $21 \%$, respectively, and are dependent on strong laboratory infrastructure. ${ }^{18,19}$

Other systematic reviews of STI prevalence in pregnant women have found similarly high rates of STIs. A review article by Chico et al. ${ }^{16}$ in 2012 found that the prevalence of syphilis was $3.5 \%$, CT was $6.1 \%$ and TV was $17.8 \%$ among pregnant women in West and Central Africa. Those rates are similar to the mean prevalences we report, which include 41 additional studies from sub-Saharan Africa and expand the review to include a large proportion of low- and middle-income countries.

Despite persistent high level of STIs among pregnant women, there is still a limited focus on CT, NG, and TV. All of those are curable STIs that are risk factors for adverse birth and neonatal outcomes. Despite the well-known negative outcomes of these curable STIs, our systematic review revealed a serious lack of necessary prevalence data, which impedes an accurate assessment of the STIs among pregnant women in multiple regions worldwide, thereby preventing the timely diagnosis and treatment of pregnant women (and their partners and infants) to prevent known complications.

Our findings are particularly relevant for $\mathrm{CT}$ and $\mathrm{NG}$, which are largely asymptomatic infections. However, TV and syphilis, which may present with the symptoms of genital discharge and ulceration, also go underdiagnosed. ${ }^{8}$ In the past, it was difficult to determine whether women had CT or NG because the performance of the available tests was poor. Now, with the advent of point-of-care NAATs, the specificity and sensitivity of CT and NG 
tests are much higher and may be cost-effective to use in resource-limited countries. ${ }^{24}$ As a testament to the success that can be had with STI screening, point-of-care rapid syphilis tests are now being integrated into antenatal care around the world, and some countries have even started to use a dual syphilis-HIV test, which has shown excellent performance. ${ }^{25}$ Our study found that most of the syphilis testing was done with point-of-care tests, whereas none of the other STI tests were point of care.

\section{LIMITATIONS}

Our study was subject to some limitations. We only used PubMed for the search and may have missed other publications as a result. Although PubMed (Medline) and EMBASE are similar, their coverage of the published literature differs. For example, EMBASE is used more frequently in Europe, and PubMed in the United States. As a result of limiting our search to PubMed, we may have excluded European or abstract citations. Further, the quality of the studies included in this analysis varied considerably, including different sampling strategies, diagnostic tests used, testing strategies, and HIV coinfection rates. We attempted to control for that heterogeneity by adjusting for women's mean age, sensitivity of diagnostic test used (when reported), and number of women included in the sample size. Our estimates though may be underestimations because we excluded studies on sex workers $(n=$ 2) and symptomatic women. Additionally, in countries with limited access to STI care, the prevalence studies often used convenience sampling, which may underestimate the true burden in pregnancy. Also, diagnostic tests with poor sensitivity will tend to underdiagnose true-positive cases and underreport STI prevalence as a result. Conversely, studies not performing treponemal specific testing may overreport syphilis prevalence. The limited number of studies on NG and TV might limit generalizability or precision of the estimates. Where possible, we included more than 2 studies; however, there were instances where more than 1 recent study was not available (eg, CT in West Africa, NG and TV in Asia). We excluded studies that only reported estimates of STI prevalence, but did not present data as to where those estimates came from (eg, surveys, subjective or self-reported estimates), which could have caused underrepresentation of studies from West and Central Africa or Asia. Finally, due to the significant heterogeneity in socioeconomic status within each region, regional prevalence studies may not be representative of population-level burden of STIs among pregnant women.

\section{CONCLUSIONS}

Our study highlights the urgent need to collect reliable measures of STI prevalence in lowand middle-income countries, where the burden among pregnant women is greatest. We advocate for strengthening prevalence monitoring as a method of STI surveillance in pregnant women worldwide. ${ }^{26}$ The sequelae of untreated STIs are well known. ${ }^{1-9}$ However, the syndromic approach continues to direct STI management among pregnant women in low- and middle-income countries, which substantially underdetects STI prevalence in pregnant women. ${ }^{12,15}$ Additional focus is needed to expand the clinical evidence for policy makers on the cost-effectiveness of integrating CT, NG, and TV screening and diagnostics into existing antenatal care programs already focusing on syphilis and HIV. In conclusion, the prevalence of curable STIs is substantial among pregnant women in low- and middle- 
income countries in all regions, suggesting a large population-level burden of untreated curable infections. Our study revealed a lack of necessary prevalence data among pregnant women in low- and middle-income countries, where the disease burden is greatest. The lack of reliable prevalence data not only impedes an accurate assessment of STIs among pregnant women in multiple regions worldwide, but also prevents the treatment of pregnant women to prevent adverse pregnancy and neonatal health outcomes. Data from systematic and comprehensive screening programs in pregnancy are needed to support the design and implementation of effective prevention and control strategies in low- and middle-income countries.

\section{Appendix 1 Search terms used}

("sexually transmitted infections" [text word] OR "sexually transmitted diseases" [text word] OR "genital tract infections" [text word] OR "reproductive tract infections"[text word] OR "syphilis"[text word] OR "treponema pallidum"[text word] OR "gonorrhea"[text word] OR "Neisseria gonorrhoeae"[text word] OR "chlamydia"[text word] OR "chlamydia trachomatis" [text word] OR "trichomonas"[text word] OR "trichomonas vaginalis" [text word] OR "sexually transmitted diseases, bacterial" [Mesh] OR "reproductive tract infections"[Mesh]OR"trichomonas"[Mesh] OR “treponema pallidum”[Mesh] OR "chlamydia" [Mesh] OR "Neisseria gonorrhoeae"[Mesh])

AND

("pregnancy" [text word] OR "pregnant women" [text word] OR "antenatal" [text word] OR "pregnant women" [Mesh] OR "pregnancy" [Mesh] OR "prenatal care" [Mesh] OR "perinatal care" [Mesh])

AND

("developing country"[text word] OR "developing countries" [text word] OR "Africa”[text word] OR "Mexico"[text word] OR "Caribbean" [text word] OR "central America”[text word] OR "Latin America" [text word] OR "south America"[text word] OR "Americas"[text word] OR "Asia"[text word] OR "China" [text word] OR "Oceania"[text word] OR "Eastern Europe"[text word] OR "developing countries"[Mesh] OR "Africa"[Mesh] OR "Mexico" [Mesh] OR "Caribbean region"[Mesh] OR "central America"[Mesh] OR "Latin America" [Mesh] OR "south America” [Mesh] OR “Asia”[Mesh] OR “Transcaucasia”[Mesh] OR "Indian ocean islands"[Mesh] OR "Pacific Islands"[Mesh] OR "Europe, eastern”[Mesh])

AND

("prevalence" [Mesh] OR "morbidity" [Mesh] OR "epidemiology" [Subheading] OR "statistics and numerical data" [Subheading] OR prevalence [text word] OR morbidity [text word] OR epidemiology [text word] OR statistic*[text word])NOT ("animals" [Mesh] NOT "humans" [Mesh]) 


\section{Appendix 2 Publications included in analysis}

\section{References}

1. Wangnapi RA, Soso S, Unger HW, Sawera C, Ome M, Umbers AJ, et al. Prevalence and risk factors for Chlamydia trachomatis, Neisseria gonorrhoeae and Trichomonas vaginalis infection in pregnant women in Papua New Guinea. Sex Transm Infect. 2015 May; 91(3):194-200. Epub 2014 Oct 13. DOI: 10.1136/sextrans-2014-051670 [PubMed: 25313204]

2. Cabeza J, García PJ, Segura E, García P, Escudero F, La Rosa S, León S, et al. Feasibility of Chlamydia trachomatis screening and treatment in pregnant women in Lima, Peru: a prospective study in two large urban hospitals. Sex Transm Infect. 2015 Feb; 91(1):7-10. Epub 2014 Aug 8. DOI: 10.1136/sextrans-2014-051531 [PubMed: 25107711]

3. Chopra S, Garg A, Chopra M, Ghosh A, Sreenivas V, Sood S, et al. Declining trends of Syphilis seroprevalance among antenatal clinic cases and STD clinic cases in a tertiary care centre: from January 2002 to December 2012. Indian J Med Microbiol. 2015 Feb.(33 Suppl):126-8. DOI: 10.4103/0255-0857.150917 [PubMed: 25657130]

4. Lawi JD, Mirambo MM, Magoma M, Mushi MF, Jaka HM, Gumodoka B, et al. Sero-conversion rate of Syphilis and HIV among pregnant women attending antenatal clinic in Tanzania: a need for re-screening at delivery. BMC Pregnancy Childbirth. 2015 Jan.15:22. 3.doi: 10.1186/ s12884-015-0434-2 [PubMed: 25884884]

5. Unger HW, Ome-Kaius M, Wangnapi RA, Umbers AJ, Hanieh S, Suen CS, et al. Sulphadoxinepyrimethamine plus azithromycin for the prevention of low birthweight in Papua New Guinea: a randomised controlled trial. BMC Med. 2015 Jan.13:16. 9. doi: [PubMed: 25622597]

6. Manabe YC, Namale G, Nalintya E, Sempa J, Ratanshi RP, Pakker N, Katabira E. Integration of antenatal syphilis screening in an urban HIV clinic: a feasibility study. BMC Infect Dis. 2015 Jan. 15:13. 15.doi: 10.1186/s12879-014-0739-1 [PubMed: 25582884]

7. Moodley D, Moodley P, Sebitloane M, Soowamber D, McNaughton-Reyes HL, Groves AK, Maman S. High prevalence and incidence of asymptomatic sexually transmitted infections during pregnancy and postdelivery in KwaZulu Natal, South Africa. Sex Transm Dis. 2015 Jan; 42(1):43-7. DOI: 10.1097/OLQ.0000000000000219 [PubMed: 25504300]

8. Taylor MM, Ebrahim S, Abiola N, Kinkodi DK, Mpingulu M, Kabuayi JP, et al. Correlates of syphilis seropositivity and risk for syphilis-associated adverse pregnancy outcomes among women attending antenatal care clinics in Democratic Republic of Congo. Int J STD AIDS. 2014 Sep; 25(10):716-25. Epub 2014 Jan 22. DOI: 10.1177/0956462413518194 [PubMed: 24452733]

9. De Paschale M, Ceriani C, Cerulli T, Cagnin D, Cavallari S, Cianflone A, et al. Antenatal screening for Toxoplasma gondii, Cytomegalovirus, rubella and Treponema pallidum infections in northern Benin. Trop Med Int Health. 2014 Jun; 19(6):743-746. Epub 2014 Mar 10. DOI: 10.1111/tmi.12296 [PubMed: 24612218]

10. Abdelaziz ZA, Ibrahim ME, Bilal NE, Hamid ME. Vaginal infections among pregnant women at Omdurman Maternity Hospital in Khartoum, Sudan. J Infect Dev Ctries. 2014 Apr; 8(4):15. 4907. DOI: $10.3855 /$ jidc. 3197

11. Soeiro CM, Miranda AE, Saraceni V, Santos MC, Talhari S, Ferreira LC. Syphilis in pregnancy and congenital syphilis in Amazonas State, Brazil: an evaluation using database linkage. Cad Saude Publica. 2014 Apr; 30(4):715-23. [PubMed: 24896047]

12. Hong FC, Yang YZ, Liu XL, Feng TJ, Liu JB, Zhang CL, Lan LN, Yao MZ, Zhou H. Reduction in mother-to-child transmission of syphilis for 10 years in Shenzhen, China. Sex Transm Dis. 2014 Mar; 41(3):188-93. DOI: 10.1097/OLQ.0000000000000097 [PubMed: 24521725]

13. Archana BR, Prasad SR, Beena PM, Okade R, Sheela SR, Beeregowda YC. Maternal and congenital syphilis in Karnataka, India. Southeast Asian J Trop Med Public Health. 2014 Mar; 45(2):430-4. [PubMed: 24968685]

14. Sánchez-Gómez A, Grijalva MJ, Silva-Aycaguer LC, Tamayo S, Yumiseva CA, Costales JA, et al. HIV and syphilis infection in pregnant women in Ecuador: prevalence and characteristics of antenatal care. Sex Transm Infect. 2014 Feb; 90(1):70-5. Epub 2013 Nov 26. DOI: 10.1136/ sextrans-2013-051191 [PubMed: 24282329] 
15. Qin JB, Feng TJ, Yang TB, Hong FC, Lan LN, Zhang CL, et al. Risk factors for congenital syphilis and adverse pregnancy outcomes in offspring of women with syphilis in Shenzhen, China: a prospective nested case-control study. Sex Transm Dis. 2014 Jan; 41(1):13-23. DOI: 10.1097/ OLQ.0000000000000062 [PubMed: 24326577]

16. Rahman M, Chowdhury SB, Akhtar N, Jahan M, Jahan MK, Jebunnahar S. Chlamydia trachomatis IgM seropositivity during pregnancy and assessment of its risk factors. Mymensingh Med J. 2014 Jan; 23(1):62-8. [PubMed: 24584375]

17. van den Broek NR, Jean-Baptiste R, Neilson JP. Factors associated with preterm, early preterm and late preterm birth in Malawi. PLoS One. 2014 Mar 3.9(3):e90128. eCollection 2014. doi: 10.1371/ journal.pone.0090128 [PubMed: 24595186]

18. Jespers V, Crucitti T, Menten J, Verhelst R, Mwaura M, Mandaliya K, et al. Prevalence and correlates of bacterial vaginosis in different sub-populations of women in sub-Saharan Africa: a cross-sectional study. PLoS One. 2014 Oct 7.9(10):e109670. eCollection 2014. doi: 10.1371/ journal.pone.0109670 [PubMed: 25289640]

19. Mobasheri M, Saeedi Varnamkhast N, Karimi A, Banaeiyan S. Prevalence study of genital tract infections in pregnant women referred to health centers in Iran. Turk J Med Sci. 2014; 44(2):2326. [PubMed: 25536729]

20. Dinh TH, Kamb ML, Msimang V, Likibi M, Molebatsi T, Goldman T, Lewis DA. Integration of preventing mother-to-child transmission of HIVand syphilis testing and treatment in antenatal care services in the Northern Cape and Gauteng provinces, South Africa. Sex Transm Dis. 2013 Nov; 40(11):846-51. DOI: 10.1097/OLQ.0000000000000042 [PubMed: 24113405]

21. Borborema-Alfaia AP, Freitas NS, Astolfi Filho S, Borborema-Santos CM. Chlamydia trachomatis infection in a sample of northern Brazilian pregnant women: prevalence and prenatal importance. Braz J Infect Dis. 2013 Sep-Oct;17(5):545-50. Epub 2013 Jul 4. DOI: 10.1016/j.bjid.2013.01.014 [PubMed: 23831212]

22. Berini CA, Delfino C, Torres O, García G, Espejo R, Pianciola L, et al. HTLV-1 cosmopolitan and HTLV-2 subtype $b$ among pregnant women of non-endemic areas of Argentina. Sex Transm Infect. 2013 Jun; 89(4):333-5. Epub 2012 Dec 8. DOI: 10.1136/sextrans-2012-050594 [PubMed: 23220782]

23. Agholor K, Omo-Aghoja L, Okonofua F. Association of anti-Chlamydia antibodies with ectopic pregnancy in Benin city, Nigeria: a case-control study. Afr Health Sci. 2013 Jun; 13(2):430-40. DOI: 10.4314/ahs.v13i2.33 [PubMed: 24235946]

24. Araújo MA, de Freitas SC, de Moura HJ, Gondim AP, da Silva RM. Prevalence and factors associated with syphilis in parturient women in Northeast, Brazil. BMC Public Health. 2013 Mar. 13:7. 206.doi: 10.1186/1471-2458-13-206 [PubMed: 23289729]

25. Nóbrega I, Dantas P, Rocha P, Rios I, Abraão M, Netto EM, Brites C. Syphilis and HIV-1 among parturient women in Salvador, Brazil: low prevalence of syphilis and high rate of loss to follow-up in HIV-infected women. Braz J Infect Dis. 2013 Mar-Apr;17(2):184-93. Epub 2013 Feb 28. DOI: 10.1016/j.bjid.2012.10.018 [PubMed: 23453946]

26. Karaer A, Mert I, Cavkaytar S, Batioglu S. Serological investigation of the role of selected sexually transmitted infections in the aetiology of ectopic pregnancy. Eur J Contracept Reprod Health Care. 2013 Feb; 18(1):68-74. Epub 2012 Dec 21. DOI: 10.3109/13625187.2012.744818 [PubMed: 23256948]

27. Abdelaziz ZA, Ibrahim ME, Bilal NE, Hamid ME. Vaginal infections among pregnant women at Omdurman Maternity Hospital in Khartoum, Sudan. J Infect Dev Ctries. :201.

28. Borborema-Alfaia AP, Freitas NS, Astolfi Filho S, Borborema-Santos CM. Chlamydia trachomatis infection in a sample of northern Brazilian pregnant women: prevalence and prenatal importance. Braz J Infect Dis. 2013 Sep-Oct;17(5):545-50. Epub 2013 Jul 4. 4 Apr 15;8(4)490-7. doi: 10.3855/jidc.3197. DOI: 10.1016/j.bjid.2013.01.014 [PubMed: 23831212]

29. De Jongh M, Lekalakala MR, Le Roux M, Hoosen AA. Risk of having a sexually transmitted infection in women presenting at a termination of pregnancy clinic in Pretoria, South Africa. J Obstet Gynaecol. 2010; 30(5):480-3. DOI: 10.3109/01443611003797687 [PubMed: 20604651]

30. Temmerman M, Gichangi P, Fonck K, Apers L, Claeys P, Van Renterghem L, et al. Effect of a syphilis control programme on pregnancy outcome in Nairobi, Kenya. Sex Transm Infect. 2000 Apr; 76(2):117-21. [PubMed: 10858713] 
31. Berini CA, Delfino C, Torres O, García G, Espejo R, Pianciola L, et al. HTLV-1 cosmopolitan and HTLV-2 subtype $\mathrm{b}$ among pregnant women of non-endemic areas of Argentina. Sex Transm Infect. 2013 Jun; 89(4):333-5. Epub 2012 Dec 8. DOI: 10.1136/sextrans-2012-050594 [PubMed: 23220782]

32. Agholor K, Omo-Aghoja L, Okonofua F. Association of anti-Chlamydia antibodies with ectopic pregnancy in Benin city, Nigeria: a case-control study. Afr Health Sci. 2013 Jun; 13(2):430-40. DOI: 10.4314/ahs.v13i2.33 [PubMed: 24235946]

33. Araújo MA, de Freitas SC, de Moura HJ, Gondim AP, da Silva RM. Prevalence and factors associated with syphilis in parturient women in Northeast, Brazil. BMC Public Health. 2013 Mar. 13:7. 206.doi: 10.1186/1471-2458-13-206 [PubMed: 23289729]

34. Nóbrega I, Dantas P, Rocha P, Rios I, Abraão M, Netto EM, Brites C. Syphilis and HIV-1 among parturient women in Salvador, Brazil: low prevalence of syphilis and high rate of loss to follow-up in HIV-infected women. Braz J Infect Dis. 2013 Mar-Apr;17(2):184-93. Epub 2013 Feb 28. DOI: 10.1016/j.bjid.2012.10.018 [PubMed: 23453946]

35. Karaer A, Mert I, Cavkaytar S, Batioglu S. Serological investigation of the role of selected sexually transmitted infections in the aetiology of ectopic pregnancy. Eur J Contracept Reprod Health Care. 2013 Feb; 18(1):68-74. Epub 2012 Dec 21. DOI: 10.3109/13625187.2012.744818 [PubMed: 23256948]

36. Domingues RM, Saracen V, Hartz ZM, Leal Mdo C. Congenital syphilis: a sentinel event in antenatal care quality. Rev Saude Publica. 2013 Feb; 47(1):147-56. discussion 157. English, Portuguese. [PubMed: 23703141]

37. Frickmann H, Schwarz NG, Girmann M, Hagen RM, Poppert S, Crusius S, Podbielski A, et al. Serological survey of HIV and syphilis in pregnant women in Madagascar. Trop Med Int Health. 2013 Jan; 18(1):35-9. Epub 2012 Oct 24. DOI: 10.1111/tmi.12007 [PubMed: 23094758]

38. Reuschel E, Tibananuka S, Seelbach-Goebel B. HIV-1 seroprevalence among pregnant women in rural Uganda: a longitudinal study over fifteen years. Gynecol Obstet Invest. 2013; 75(3):169-74. Epub 2013 Mar 6. DOI: 10.1159/000346175 [PubMed: 23486005]

39. Yang LG, Tucker JD, Liu FY, Ren XQ, Hong X, Wang C, et al. Syphilis screening among 27,150 pregnant women in South Chinese rural areas using point-of-care tests. PLoS One. 2013 Aug 29.8(8):e72149. eCollection 2013. doi: 10.1371/journal.pone.0072149 [PubMed: 24009673]

40. Strasser S, Bitarakwate E, Gill M, Hoffman HJ, Musana O, Phiri A, et al. Introduction of rapid syphilis testing within prevention of mother-to-child transmission of HIV programs in Uganda and Zambia: a field acceptability and feasibility study. J Acquir Immune Defic Syndr. 2012 Nov 1; 61(3):e40-6. DOI: 10.1097/QAI.0b013e318267bc94 [PubMed: 22820810]

41. Ormaeche M, Whittembury A, Pun M, Suárez-Ognio L. Hepatitis B virus, syphilis, and HIV seroprevalence in pregnant women and their male partners from six indigenous populations of the Peruvian Amazon Basin, 2007-2008. Int J Infect Dis. 2012 Oct; 16(10):e724-30. Epub 2012 Aug 9. DOI: 10.1016/j.ijid.2012.05.1032 [PubMed: 22884008]

42. Yáñez-Alvarez I, Conde-González CJ, Uribe-Salas FJ, Olamendi-Portugal ML, García-Cisneros S, Sánchez-Alemán MA. Maternal/child seroprevalence of antibodies against Treponema pallidum at four general hospitals in the state of Morelos, Mexico. Arch Med Res. 2012 Oct; 43(7):571-7. Epub 2012 Oct 16. DOI: 10.1016/j.arcmed.2012.10.001 [PubMed: 23085448]

43. Sequeira CG, Tamegão-Lopes BP, Santos EJ, Ventura AM, Moraes-Pinto MI, Succi RC. Descriptive study of HTLV infection in a population of pregnant women from the state of Pará, Northern Brazil. Rev Soc Bras Med Trop. 2012 Jul-Aug;45(4):453-6. Epub 2012 Jul 26. [PubMed: 22836660]

44. Manda SO, Lombard CJ, Mosala T. Divergent spatial patterns in the prevalence of the human immunodeficiency virus (HIV) and syphilis in South African pregnant women. Geospat Health. 2012 May; 6(2):221-31. [PubMed: 22639124]

45. Chiduo M, Theilgaard ZP, Bakari V, Mtatifikolo F, Bygbjerg I, Flanholc L, Gerstoft J, et al. Prevalence of sexually transmitted infections among women attending antenatal clinics in Tanga, north eastern Tanzania. Int J STD AIDS. 2012 May; 23(5):325-9. DOI: 10.1258/ijsa.2011.011312 [PubMed: 22648885]

46. Tornatore M, Gonçalves CV, Bianchi MS, Germano FN, Garcés AX, Soares MA, Machado ES, de Martinez AM. Co-infections associated with human immunodeficiency virus type 1 in pregnant 
women from southern Brazil: high rate of intraepithelial cervical lesions. Mem Inst Oswaldo Cruz. 2012 Mar; 107(2):205-10. [PubMed: 22415259]

47. Makasa M, Fylkesnes K, Michelo C, Kayeyi N, Chirwa B, Sandoy I. Declining syphilis trends in concurrence with HIV declines among pregnant women in Zambia: observations over 14 years of national surveillance. Sex Transm Dis. 2012 Mar; 39(3):173-81. DOI: 10.1097/OLQ. 0b013e31823b23a4 [PubMed: 22337102]

48. Hong H, Xu GZ, Zhang DD. Voluntary counseling and testing services for HIVand sexually transmitted infections among pregnant women in China. Int J Gynaecol Obstet. 2012 Feb; 116(2): 173-4. Epub 2011 Nov 23. DOI: 10.1016/j.ijgo.2011.08.020 [PubMed: 22114784]

49. Vidwan NK, Regi A, Steinhoff M, Huppert JS, Staat MA, Dodd C, et al. Low prevalence of Chlamydia trachomatis infection in non-urban pregnant women in Vellore, S. India. PLoS One. 2012; 7(5):e34794. Epub 2012 May 2. doi: 10.1371/journal.pone.0034794 [PubMed: 22567090]

50. Shah SA, Kristensen S, Memon MA, Usman G, Ghazi A, John R, Sathiakumar N, Vermund SH. Prevalence of syphilis among antenatal clinic attendees in Karachi: imperative to begin universal screening in Pakistan. J Pak Med Assoc. 2011 Oct; 61(10):993-7. [PubMed: 22356034]

51. Pinto VM, Szwarcwald CL, Baroni C, Stringari LL, Inocêncio LA, Miranda AE. Chlamydia trachomatis prevalence and risk behaviors in parturient women aged 15 to 24 in Brazil. Sex Transm Dis. 2011 Oct; 38(10):957-61. DOI: 10.1097/OLQ.0b013e31822037fc [PubMed: 21934572]

52. Johri M, Morales RE, Boivin JF, Samayoa BE, Hoch JS, Grazioso CF, et al. Increased risk of miscarriage among women experiencing physical or sexual intimate partner violence during pregnancy in Guatemala City, Guatemala: cross-sectional study. BMC Pregnancy Childbirth. 2011 Jul.11:6. 49.doi: 10.1186/1471-2393-11-49 [PubMed: 21244665]

53. Delvaux T, Samreth S, Barr-DiChiara M, Seguy N, Guerra K, Ngauv B, et al. Linked response for prevention, care, and treatment of HIV/AIDS, STIs, and reproductive health issues: results after 18 months of implementation in five operational districts in Cambodia. J Acquir Immune Defic Syndr. 2011 Jul 1; 57(3):e47-55. DOI: 10.1097/QAI.0b013e318216d5cf [PubMed: 21407084]

54. Chi BH, Vwalika B, Killam WP, Wamalume C, Giganti MJ, Mbewe R, et al. Implementation of the Zambia electronic perinatal record system for comprehensive prenatal and delivery care. Int $\mathbf{J}$ Gynaecol Obstet. 2011 May; 113(2):131-6. DOI: 10.1016/j.ijgo.2010.11.013 [PubMed: 21315347]

55. Ramos JM, Toro C, Reyes F, Amor A, Gutiérrez F. Seroprevalence of HIV-1, HBV, HTLV-1 and Treponema pallidum among pregnant women in a rural hospital in Southern Ethiopia. J Clin Virol. 2011 May; 51(1):83-5. Epub 2011 Feb 16. DOI: 10.1016/j.jcv.2011.01.010 [PubMed: 21330196]

56. Mahmud NU, Hossain MA, Nahar K, Mahmud C, Paul SK, Ahmed S, et al. Seroprevalence of genital Chlamydia trachomatis infection in women of reproductive age. Mymensingh Med J. 2011 Apr; 20(2):187-91. [PubMed: 21522085]

57. Khin-Nwe-Oo, Wah-Wah-Aung, Moe-Thida, Khin-Thet-Wai, Hta-Hta-Yi, Win-Win-Mya. Casecontrol study of ectopic pregnancies in Myanmar: infectious etiological factors. Southeast Asian J Trop Med Public Health. 2011 Mar; 42(2):347-54. [PubMed: 21710857]

58. Kirakoya-Samadoulougou F, Defer MC, Yaro S, Fao P, Ilboudo F, Langani Y, et al. Low seroprevalence of syphilis in Burkina Faso. Sex Transm Infect. 2011 Feb; 87(1):35-7. Epub 2010 Aug 5. DOI: 10.1136/sti.2010.042465 [PubMed: 20693149]

59. Mbamara SU, Obiechina NJ. Seroprevalence of venereal disease among pregnant women attending antenatal care (ANC) in Onitsha, Anambra State, Southeast, Nigeria. Niger J Med. 2011 Jan-Mar; 20(1):57-60. [PubMed: 21970261]

60. Ramos BR, Polettini J, Marcolino LD, Vieira EP, Marques MA, Tristão AR, et al. Prevalence and risk factors of Chlamydia trachomatis cervicitis in pregnant women at the genital tract infection in obstetrics unit care at Botucatu Medical School, São Paulo State University-UNESP, Brazil. J Low Genit Tract Dis. 2011 Jan; 15(1):20-4. DOI: 10.1097/LGT.0b013e3181ed3d58 [PubMed: 21192172]

61. Benzaken AS, Sabidó M, Galban E, Pedroza V, Araújo AJ, Peeling RW, Mabey D. Field performance of a rapid point-of-care diagnostic test for antenatal syphilis screening in the Amazon region, Brazil. Int J STD AIDS. 2011 Jan; 22(1):15-8. DOI: 10.1258/ijsa.2010.010145 [PubMed: 21364061] 
62. Luntamo M, Kulmala T, Mbewe B, Cheung YB, Maleta K, Ashorn P. Effect of repeated treatment of pregnant women with sulfadoxine-pyrimethamine and azithromycin on preterm delivery in Malawi: a randomized controlled trial. Am J Trop Med Hyg. 2010 Dec; 83(6):1212-20. DOI: 10.4269/ajtmh.2010.10-0264 [PubMed: 21118924]

63. Mapingure MP, Msuya S, Kurewa NE, Munjoma MW, Sam N, Chirenje MZ, Rusakaniko S, Saugstad LF, de Vlas SJ, Stray-Pedersen B. Sexual behaviour does not reflect HIV-1 prevalence differences: a comparison study of Zimbabwe and Tanzania. J Int AIDS Soc. 2010 Nov.13:16. 45.doi: 10.1186/1758-2652-13-45 [PubMed: 20409346]

64. Gonçalves MA, Matos Cde C, Spegiorin LC, Oliani DC, Oliani AH, Mattos LC. Seropositivity rates for toxoplasmosis, rubella, syphilis, cytomegalovirus, hepatitis and HIV among pregnant women receiving care at a public health service, São Paulo state, Brazil. Braz J Infect Dis. 2010 Nov-Dec;14(6):601-5. [PubMed: 21340301]

65. Kumogola Y, Slaymaker E, Zaba B, Mngara J, Isingo R, Changalucha J, et al. Trends in HIV \& syphilis prevalence and correlates of HIV infection: results from cross-sectional surveys among women attending ante-natal clinics in Northern Tanzania. BMC Public Health. 2010 Sep.10:13. 553.doi: 10.1186/1471-2458-10-553 [PubMed: 20070889]

66. Zhu L, Qin M, Du L, Xie RH, Wong T, Wen SW. Maternal and congenital syphilis in Shanghai, China, 2002 to 2006. Int J Infect Dis. 2010 Sep; 14(Suppl 3):e45-8. Epub 2010 Feb 6. DOI: 10.1016/j.ijid.2009.09.009 [PubMed: 20137991]

67. Samayoa B, Anderson MR, Alonso Pacheco KP, Lee C, Pittard A, Soltren A, et al. Seroprevalence of HIV, hepatitis B, and syphilis among pregnant women at the general hospital, Guatemala City, 2005-2009. J Int Assoc Physicians AIDS Care (Chic). 2010 Sep-Oct;9(5):313-7. Epub 2010 Sep 14. DOI: $10.1177 / 1545109710376669$ [PubMed: 20841440]

68. Gondo DC, Duarte MT, da Silva MG, de Lima Parada CM. Abnormal vaginal flora in low-risk pregnant women cared for by a public health service prevalence and association with symptoms and findings from gynecological exams. Rev Lat Am Enfermagem. 2010 Sep-Oct;18(5):919-27. [PubMed: 21120411]

69. Malope-Kgokong BI, Macphail P, Mbisa G, Ratshikhopha E, Maskew M, Stein L, et al. Kaposi's Sarcoma Associated-Herpes Virus (KSHV) Seroprevalence in Pregnant Women in South Africa. Infect Agent Cancer. 2010 Aug.5:31. 14.doi: 10.1186/1750-9378-5-14

70. Marx G, John-Stewart G, Bosire R, Wamalwa D, Otieno P, Farquhar C. Diagnosis of sexually transmitted infections and bacterial vaginosis among HIV-1-infected pregnant women in Nairobi. Int J STD AIDS. 2010 Aug; 21(8):549-52. DOI: 10.1258/ijsa.2010.010005 [PubMed: 20975086]

71. Pereira SM, Etlinger D, Aguiar LS, Peres SV, Longatto Filho A. Simultaneous Chlamydia trachomatis and HPV infection in pregnant women. Diagn Cytopathol. 2010 Jun; 38(6):397-401. DOI: 10.1002/dc.21219 [PubMed: 19859972]

72. Emmanuel SK, Lado M, Amwayi S, Abade AM, Oundo JO, Ongus JR. Syphilis among pregnant women in Juba, Southern Sudan. East Afr Med J. 2010 May; 87(5):192-8. [PubMed: 23057281]

73. Crucitti T, Jespers V, Mulenga C, Khondowe S, Vandepitte J, Buvé A. Trichomonas vaginalis is highly prevalent in adolescent girls, pregnant women, and commercial sex workers in Ndola, Zambia. Sex Transm Dis. 2010 Apr; 37(4):223-7. DOI: 10.1097/OLQ.0b013e3181c21f93 [PubMed: 19940808]

74. Abdalla E, Ekanem E, Said D, Arube P, Gboun M, Mohammed F. The need for a comprehensive response to HIV/AIDS in north-western Somalia: evidence from a seroprevalence survey. East Mediterr Health J. 2010 Feb; 16(2):141-5. [PubMed: 20799564]

75. Hitti J, Garcia P, Totten P, Paul K, Astete S, Holmes KK. Correlates of cervical Mycoplasma genitalium and risk of preterm birth among Peruvian women. Sex Transm Dis. 2010 Feb; 37(2): 81-5. DOI: 10.1097/OLQ.0b013e3181bf5441 [PubMed: 20051932]

76. Munjoma MW, Kurewa EN, Mapingure MP, Mashavave GV, Chirenje MZ, Rusakaniko S, Hussain A, Stray-Pedersen B. The prevalence, incidence and risk factors of herpes simplex virus type 2 infection among pregnant Zimbabwean women followed up nine months after childbirth. BMC Womens Health. 2010 Jan.10:12. 2.doi: 10.1186/1472-6874-10-2 [PubMed: 20374619]

77. Menéndez C, Castellsagué X, Renom M, Sacarlal J, Quintó L, Lloveras B, et al. Prevalence and risk factors of sexually transmitted infections and cervical neoplasia in women from a rural area of 
southern Mozambique. Infect Dis Obstet Gynecol. 2010; 2010 pii: 609315. Epub 2010 Jul 11. doi: $10.1155 / 2010 / 609315$

78. Stringer E, Read JS, Hoffman I, Valentine M, Aboud S, Goldenberg RL. Treatment of trichomoniasis in pregnancy in sub-Saharan Africa does not appear to be associated with low birth weight or preterm birth. S Afr Med J. 2010 Jan; 100(1):58-64. [PubMed: 20429491]

79. Hong FC, Liu JB, Feng TJ, Liu XL, Pan P, Zhou H, et al. Congenital syphilis: an economic evaluation of a prevention program in China. Sex Transm Dis. 2010 Jan; 37(1):26-31. DOI: 10.1097/OLQ.0b013e3181b3915b [PubMed: 19734825]

80. Temmerman M, Gichangi P, Fonck K, Apers L, Claeys P, Van Renterghem L, et al. Effect of a syphilis control programme on pregnancy outcome in Nairobi, Kenya. Sex Transm Infect. 2000 Apr; 76(2):117-21. [PubMed: 10858713]

81. Thompson DA, Tsai YK, Gilman RH, Vivar A, Calderon M. Sexually transmitted diseases in a family planning and an antenatal clinic in Peru: limitations of current practices and analysis of the use of potential markers, pH testing, and Whiff testing. Sex Transm Dis. 2000 Aug; 27(7):386-92. [PubMed: 10949429]

82. Aydin Y, Atis A, Ocer F, Isenkul R. Association of cervical infection of Chlamydia trachomatis, Ureaplasma urealyticum and Mycoplasma hominis with peritoneum colonisation in pregnancy. $\mathrm{J}$ Obstet Gynaecol. 2010; 30(8):809-12. DOI: 10.3109/01443615.2010.519063 [PubMed: 21126118]

\section{References}

1. Liu L, Johnson H, Cousens L, et al. Global, regional, and national causes of child mortality: an updated systematic analysis for 2010 with time trends since 2000. Lancet. 2012; 379:2151-2161. [PubMed: 22579125]

2. Mullick S, Watson-Jones D, Beksinska M, et al. Sexually transmitted infections in pregnancy: prevalence, impact on pregnancy outcomes, and approach to treatment in developing countries. Sex Transm Infect. 2005; 81:294-302. [PubMed: 16061534]

3. Adachi K, Klausner JD, Bristow CC, et al. Chlamydia and Gonorrhea in HIV-infected pregnant women and infant HIV transmission. Sex Transm Dis. 2015; 42:554-565. [PubMed: 26372927]

4. Rastogi S, Das B, Salhan S, et al. Effect of treatment for Chlamydia trachomatis during pregnancy. Int J Gynaecol Obstet. 2003; 80:129-137. [PubMed: 12566185]

5. Mårdh PA. Influence of infection with Chlamydia trachomatis on pregnancy outcome, infant health and life-long sequelae in infected offspring. Best Pract Res Clin Obstet Gynaecol. 2002; 16:847864. [PubMed: 12473286]

6. Griffin M, Pushpanathan C, Andrews W. Chlamydia trachomatis pneumonitis: a case study and literature review. Pediatr Pathol. 1990; 10:843-852. [PubMed: 2172948]

7. Mann JR, Mcdermott S, Gill T. Sexually transmitted infection is associated with increased risk of preterm birth in South Carolina women insured by Medicaid. J Matern Fetal Neonatal Med. 2010; 23:563-568. [PubMed: 19903113]

8. Silver BJ, Guy RJ, Kaldor JM, et al. Trichomonas vaginalis as a cause of perinatal morbidity: a systematic review and meta-analysis. Sex Transm Dis. 2014; 41:369-376. [PubMed: 24825333]

9. Fichorova RN. Impact of T. vaginalis infection on innate immune responses and reproductive outcome. J Reprod Immunol. 2009; 83(1-2):185-189. [PubMed: 19850356]

10. Vermund SH. Screening for sexually transmitted infections in antenatal care is especially important among HIV-infected women. Sex Transm Dis. 2015; 42:566-568. [PubMed: 26372928]

11. Yeganeh N, Watts HD, Camarca M, et al. Syphilis in HIV-infected mothers and infants: results from the NICHD/HPTN 040 study. Pediatr Infect Dis J. 2015; 34:e52-e57. [PubMed: 25742089]

12. World Health Organization, Department of Making Pregnancy Safer and Department of Reproductive Health and Research. Standards for maternal and neonatal care, Group 1 General standards of care for healthy pregnancy and childbirth. 2007 Accessed Aug 222015.

13. Low N, Broutet N, Adu-sarkodie Y, et al. Global control of sexually transmitted infections. Lancet. 2006; 368:2001-2016. [PubMed: 17141708] 
14. Who validates elimination of mother-to-child transmission of HIVand syphilis in Cuba. Saudi Med J. 2015; 36:1018-1019. [PubMed: 26438911]

15. CDC. Sexually transmitted diseases treatment guidelines. MMWR Recommendation Rep 2015. 2015; 64(RR3):1-137.

16. Chico RM, Mayaud P, Ariti C, et al. Prevalence of malaria and sexually transmitted and reproductive tract infections in pregnancy in sub-Saharan Africa: a systematic review. JAMA. 2012; 307:2079-2086. [PubMed: 22665107]

17. Moher D, Liberati A, Tetzlaff J, et al. Preferred reporting items for systematic reviews and metaanalyses: the PRISMA statement. PLoS Med. 2009; 6:e1000097. [PubMed: 19621072]

18. Chernesky MA. The laboratory diagnosis of Chlamydia trachomatis infections. Can J Infect Dis Med Microbiol. 2005; 16:39-44. [PubMed: 18159527]

19. Ota KV, Tamari IE, Smieja M, et al. Detection of Neisseria gonorrhoeae and Chlamydia trachomatis in pharyngeal and rectal specimens using the BD Probetec ET system, the Gen-Probe Aptima Combo 2 assay and culture. Sex Transm Infect. 2009; 85:182-186. [PubMed: 19126571]

20. Patil MJ, Nagamoti JM, Metgud SC. Diagnosis of Trichomonas vaginalis from vaginal specimens by Wet Mount Microscopy, In Pouch TV Culture System, and PCR. J Glob Infect Dis. 2012; 4:2225. [PubMed: 22529623]

21. Workowski KA, Berman S. Sexually transmitted diseases treatment guidelines, 2010. MMWR Recomm Rep. 2010; 59(RR-12):1-110.

22. Cook RL, Hutchison SL, Østergaard L, et al. Systematic review: noninvasive testing for Chlamydia trachomatis and Neisseria gonorrhoeae. Ann Intern Med. 2005; 142:914-925. [PubMed: 15941699]

23. StataCorp. Stata Statistical Software: Release 13. College Station, TX: StataCorp LP; 2013.

24. Bristow CC, Leon SR, Ramos LB, et al. Laboratory evaluation of a dual rapid immunodiagnostic test for HIV and syphilis infection. J Clin Microbiol. 2015; 53:311-313. [PubMed: 25378568]

25. Huang W, Gaydos CA, Barnes MR, et al. Comparative effectiveness of a rapid point-of-care test for detection of Chlamydia trachomatis among women in a clinical setting. Sex Transm Infect. 2013; 89:108-114. [PubMed: 22984085]

26. Moss NJ, Ahrens K, Kent CK, et al. The decline in clinical sequelae of genital Chlamydia trachomatis infection supports current control strategies. J Infect Dis. 2006; 193:1336-1338. [PubMed: 16586376] 
375 studies identified through PubMed (Dates: 1/1/2010$3 / 1 / 2015$ )

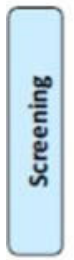

375 studies after duplicates $(n=1)$ removed
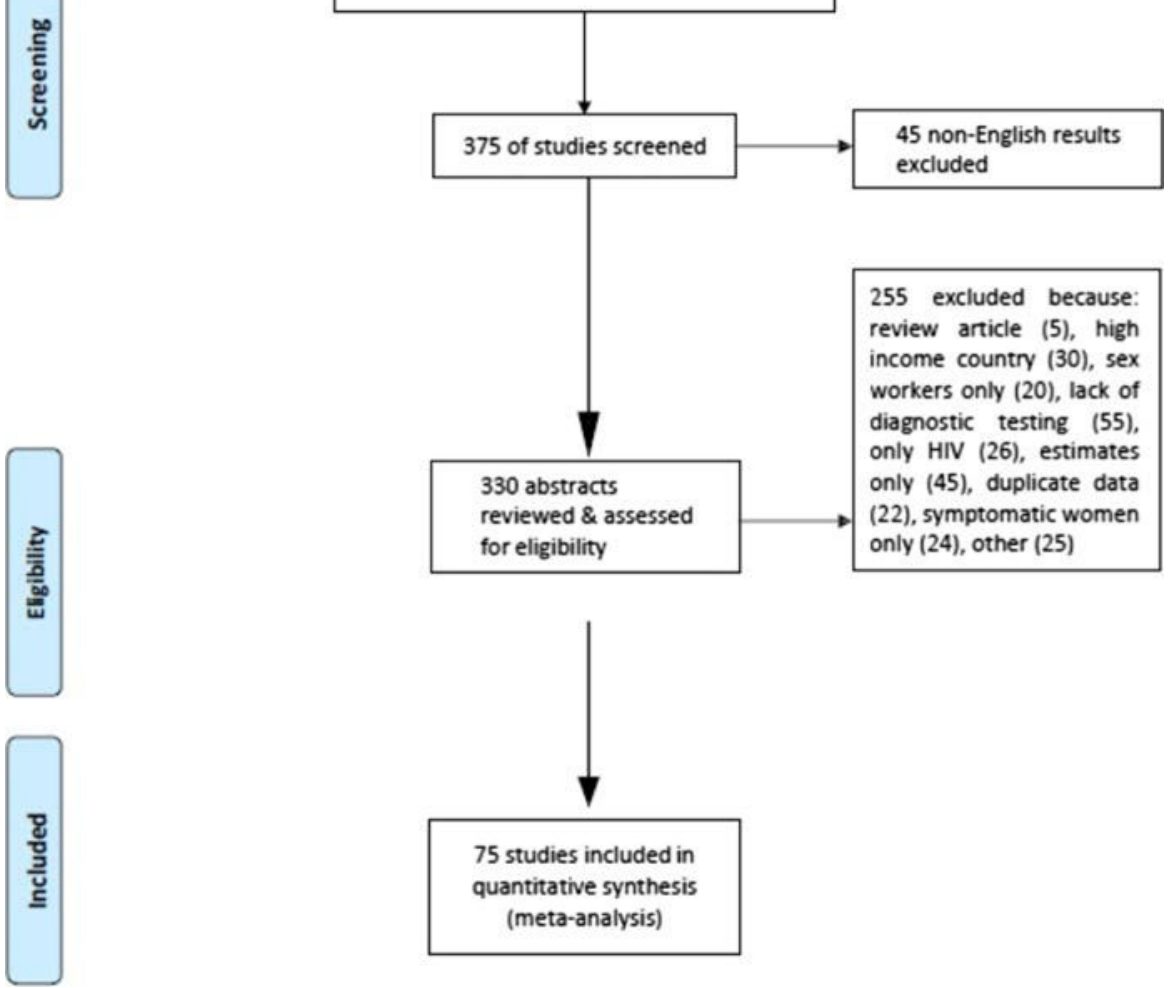

255 excluded because: review article (5), high income country (30), sex workers only (20), lack of diagnostic testing (55), only HIV (26), estimates only (45), duplicate data 330 abstracts reviewed $\&$ assessed for eligibility only (24), other (25)

75 studies included in quantitative synthesis (meta-analysis)

Figure 1.

PRISMA flow diagram of publications searched. 


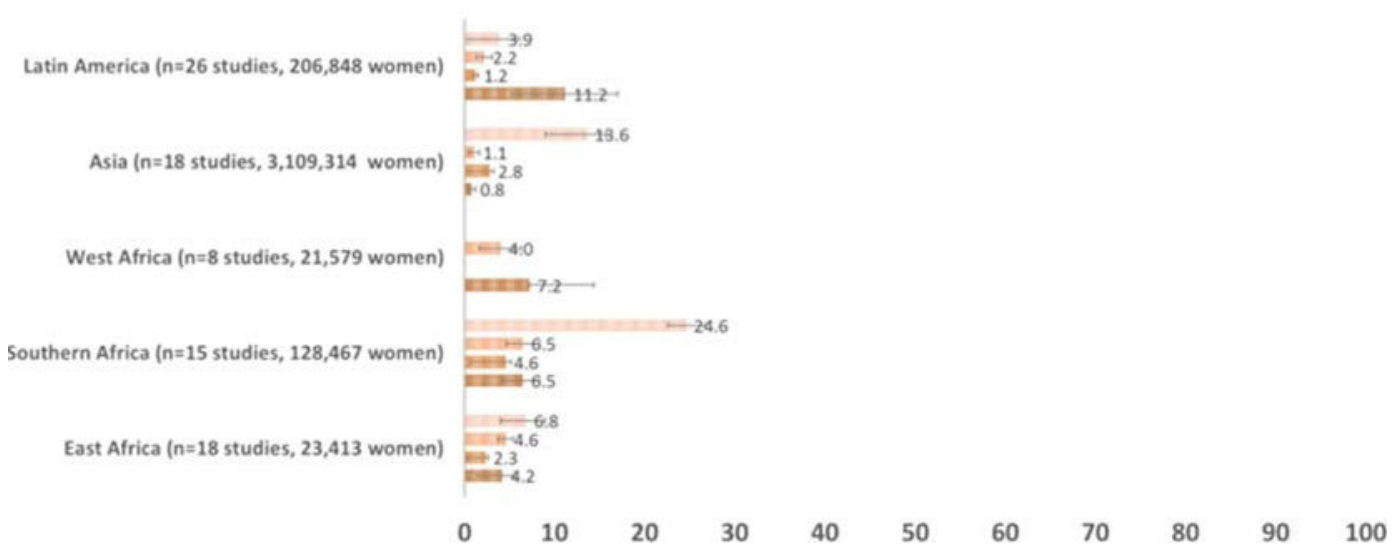

Figure 2.

Adjusted mean STI prevalence by region (N=75 studies of STI prevalence among 3,489,621 pregnant women 2010-2015). 


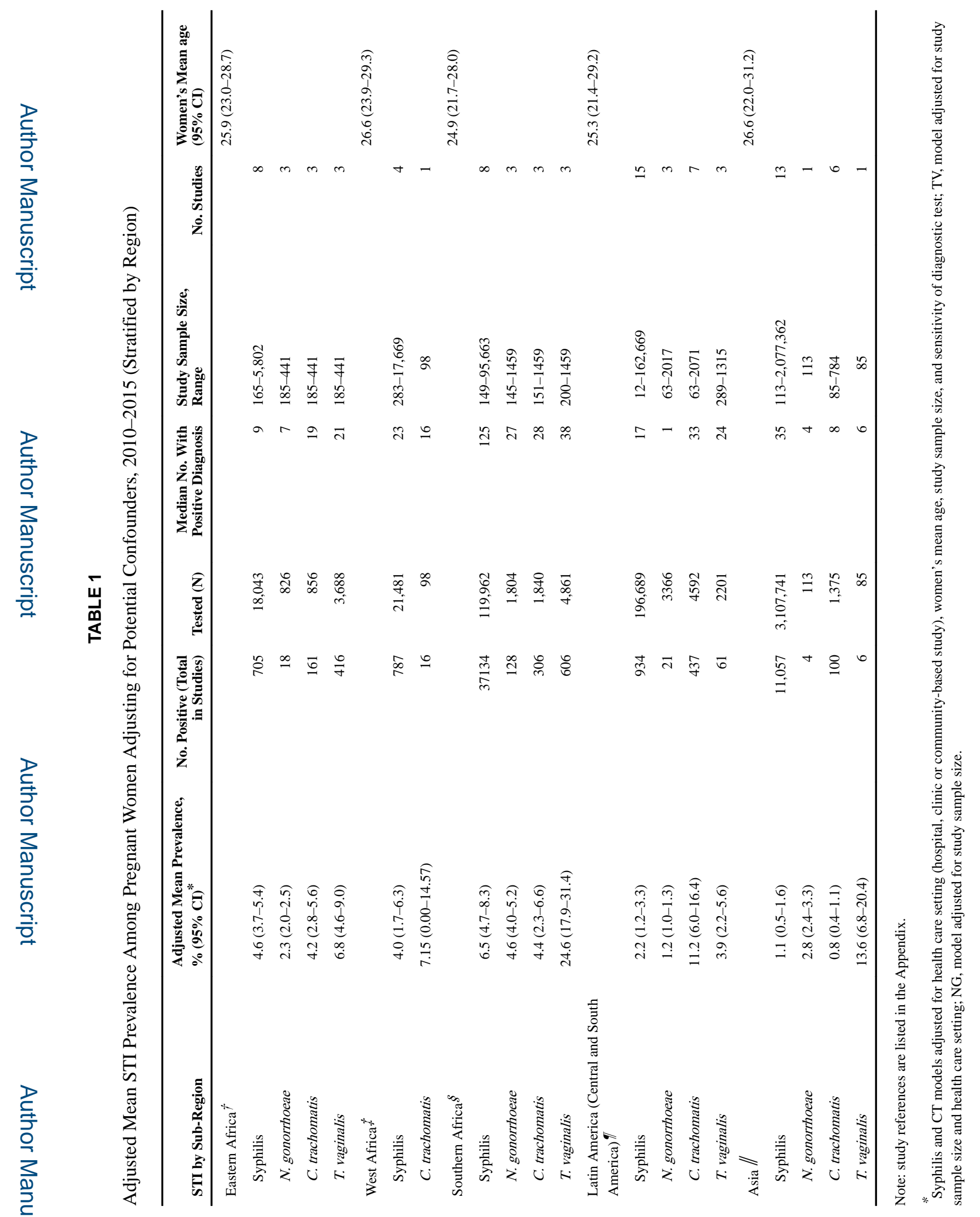

Sex Transm Dis. Author manuscript; available in PMC 2018 April 06. 


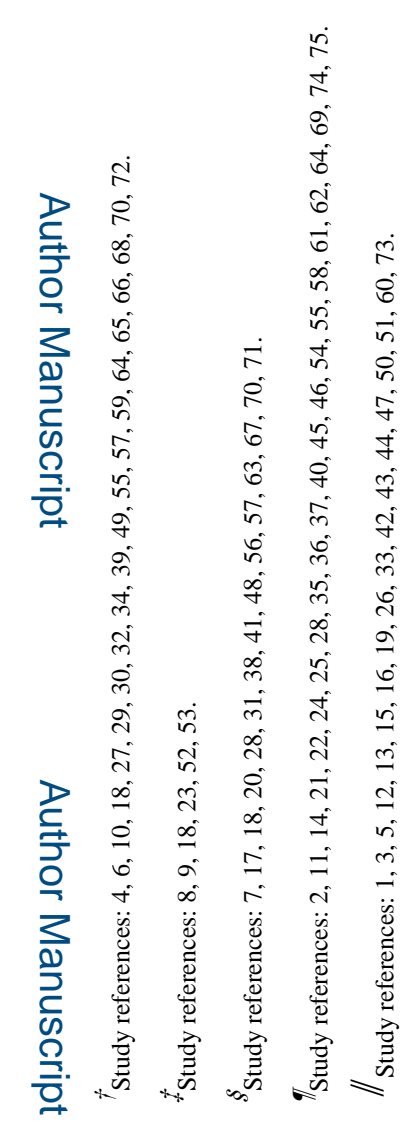

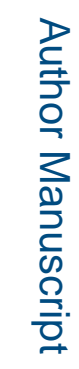

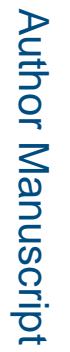

Sex Transm Dis. Author manuscript; available in PMC 2018 April 06. 